\title{
Hemşirelik Eğitiminde Kullanılan Simülasyon Yöntemlerinin Sınıflandırılması
}

\author{
Gül ŞAHIN KARADUMAN ${ }^{1}$,(D) Tülay BAŞAK²
}

'Dr., Sağlık Bilimleri Üniversitesi, Gülhane Eğitim ve Araştırma Hastanesi, Ankara, Türkiye.

${ }^{2}$ Prof.Dr., Sağlık Bilimleri Üniversitesi, Gülhane Hemşirelik Fakültesi, Ankara, Türkiye.

\section{$\ddot{O} z$}

Hemşirelik klinik eğitiminde karşılaşılan zorluklar, kısıtlı klinik uygulama süresi, COVID-19 salgını gibi durumlar öğrencilerin gerçek hastalarla olan klinik uygulama ve sürelerini olumsuz yönde etkilemektedir. Bu nedenle hemşirelik öğrencilerinin, çeşitli öğretim yaklaşımları aracılığıyla eleştirel düşünme becerileri, öğrenme ve özgüven gibi yeterlilikleri geliştirmesi amaçlanmaktadır. Simülasyona dayalı öğrenme gibi eğitim stratejileri, öğrencilere gerçeğe yakın klinik durumlar sağlayarak güvenli bir ortamda klinik uygulama yapma imkânı sunmaktadır. Simülasyon yönteminin seçiminde ise, gerçeklik kavramı önemli rol oynamaktadır. Simülasyon yöntemi ve gerçeklik düzeyinin seçimi; eğitimin hedef ve sonuçları, öğrenci seviyesi ve kolaylaştırıcı gibi faktörlere bağlıdır. Literatürde, simülasyon yöntemleri ve gerçeklik kavramı ile ilgili farklı sınıflandırmalar bulunmaktadır. Yapılan sınıflandırmalar birbirine benzer olsa da aralarında farklılıklar söz konusudur. Bu derlemede, literatürde bulunan simülasyona dayalı öğrenme özelliklerine ilişkin yapılan farklı sınıflandırmalar ve gerçeklik kavramına ilişkin tanımlamalar incelenmektedir.

Anahtar Kelimeler: Hemşirelik Eğitimi, Simülasyon, Simülasyon Sınıflandırması, Gerçeklik

Abstract
Classification of Simulation Methods Using in Nursing Education
Difficulties encountered in nursing clinical education, limited clinical practice time, and the COVID-19 outbreak negatively affect the clinical
practice and duration of students with real patients. For this reason, it is aimed to develop nursing students' competencies such as critical
thinking skills, learning and self-confidence through various teaching approaches. Educational strategies such as simulation-based education
offer students the opportunity to clinical practice in a safe environment by providing realistic clinical situations. The concept of fidelity plays
an important role in the selection of the simulation method. Selection of simulation method and fidelity level, depend on factors such as the
goals and results of the education, student level and facilitator. In the literature, there are different classifications related to simulation methods
and the concept of fidelity. Although the classifications made are similar to each other, there are also differences between them. In this review,
different classifications and definitions of fidelity regarding simulation-based education features found in the literature are examined.
Keywords: Nursing Education, Simulation, Simulation Classification, Fidelity

Geliş Tarihi / Received: 09.06.2021 Kabul Tarihi / Accepted:17.12.2021

Correspondence Author: Dr., Sağlık Bilimleri Üniversitesi, Gülhane Eğitim ve Araştırma Hastanesi, Ankara, Türkiye. E-posta: sahingl@ gmail.com.

Cite This Article: Şahin Karaduman G, Başak T. Hemşirelik Eğitiminde Kullanılan Simülasyon Yöntemlerinin Sınıflandırılması. Dokuz Eylül Üniversitesi Hemşirelik Fakültesi Elektronik Dergisi. 2022; 15(1): 78-85. 
$\mathbf{T}$ eorik ve pratik eğitimden oluşan hemşirelik eğitiminin amacı, teorik bilginin klinik uygulamaya aktarılmasını teşvik etmektir. Bu nedenle, hemşire eğitimcilerinin öğrencilere yeterli klinik deneyim sağlamaları gerekmektedir. Ancak, sınırlı klinik uygulama süresi gibi karşılaşılan çeşitli zorluklar ve günümüzün sorunu COVID-19 salgını, öğrencilerin gerçek hastalarla olan klinik uygulamaların olumsuz etkilemektedir (1). COVID-19 salgını ve yayılmasını hafifletmek için uygulanan sosyal mesafe önlemleri ise, yüz yüze eğitimin askıya alınmasına neden olmuş, mevcut eğitim ortamları çevrimiçi öğrenme ortamları ile yer değiştirmiştir (2). Bu gibi nedenlerle hemşirelik eğitimcileri, öğrencilerin klinik uygulamada karşılaşılabilecek her durumu uygulama imkânı bulamayacakları için çeşitli öğretim yaklaşımları aracıllğıyla eleştirel düşünme becerileri, öğrenme ve özgüven gibi yeterlilikleri teşvik etmeye çalışmaktadırlar. Simülasyon gibi teknolojik gelişmeler, öğrencilere gerçekçi klinik durumlar sağlayarak güvenli bir ortamda uygulama yapmalarına ve öğrenmelerine imkân tanımaktadır (1).

Sağlık bakımında simülasyonu ilk kez tanımlayan David M. Gaba simülasyonu, "gerçek dünyanın var olan önemli yönlerini çağrıştırarak veya çoğaltarak, gerçek deneyimleri rehberli deneyimlerle değiştiren bir teknik" olarak tanımlanmıştır (3). Simülasyonun tarihi yüz yıllar öncesine kadar uzanmaktadır. Simülasyonun hemşirelik eğitiminde kullanımı ise, 1950'li yıllara kadar uzanmaktadır (4). 1960'ı yıllarda tasarlanan Resusci-Anne isimli manken, 20. yüzyılın en yaygın kullanılan CPR maketinin doğuşu olmuştur. 1980'li yıllardan sonra teknoloji geliştikçe, bilgisayar yazılımları ile fizyolojik tepki ve geribildirim verebilen sistemler geliştirilmeye başlanmıştır $(5,6)$. 1990'lı yıllarda gerçekleşen tıp eğitim reformu ile sağlık eğitiminde simülasyon kullanımı gittikçe artmıştır. Günümüzde yaygınlaşarak mezuniyet öncesi ve sonrası sağlık eğitiminin ayrılmaz bir parçası haline gelmiştir (6).

Simülasyona dayalı eğitim ile teknolojinin pedagojik uygulamalarda kullanılması, öğrencilerin içerik tüketimi yoluyla değil, keşif yoluyla öğrendikleri bir öğrenme ortamı yaratmaktadır (1). Bu nedenle hemşirelik müfredatının, öğrencilerin gerekli klinik rotasyonları tamamlamalarına yardımcı olmaları için simülasyon kullanımını içerecek şekilde oluşturulması gerekmektedir (7). Uluslararası Hemşirelik Klinik Simülasyon ve Öğrenme Derneği (INACSL) ve Sağlıkta Simülasyon Derneği (SSH) de, COVID-19 salgınının neden olduğu kriz sırasında, çevrimiçi/sanal simülasyon yöntemlerinin klinik deneyimlerin yerine kullanılmasına izin verme konusunda esnek olunması gerektiğini bildirmektedir (8). Klinik öğretimin tamamlayıcısı olan bu strateji, COVID-19 salgını boyunca klinik saatlerin yerine kullanmak için potansiyel bir çözüm olarak sunulmaktadır (7). Bu teknolojik öğrenme aracını kullanmayı düşünürken ki önemli faktör ise, öğrenmeyi destekleyip desteklemediği ve eğitim/uygulama hedeflerine ulaşmayı kolaylaştırıp kolaylaştırmadığıdır (2).

Yaratıcılık, iş birliği, süreklilik, maliyet etkinliği ve zamanının korunması için simülasyon kaynaklarının seçimi ve gözden geçirilmesi gerekmektedir. Seçilen simülasyon yönteminin; ders müfredatı, öğrenme hedef ve sonuçları ile uyum içinde, öğrenciler için etkileşimli ve sürekli bir keşif temeli oluşturması gerekmektedir (9). Günümüzde hemşirelik öğrencilerinin, çevrimiçi eğitim, web tabanlı simülasyonlar gibi eğitim uygulama ve materyallerine erişimi gün geçtikçe artmaktadır. Hemşirelik eğitiminde bilgisayar teknolojileri simülasyon eğitiminin kullanımını hızlandırmakta, deneysel öğrenmeyi geliştirmekte ve uzaktan eğitimi kolaylaştırmaktadır (10). Uzaktan hemşirelik eğitiminin etkinliği ise, iyi yapılandırılmış programlara bağlanmaktadır (11).

Hemşirelik eğitiminde simülasyon kullanımının incelendiği çalışmalara bakıldığında, hasta simülasyonlarının değerlendirildiği bir çalışmada, kontrol gruplarına kıyasla simülasyon eğitimi alan katılımcılarda çeşitli alanlarda müdahale sonrası önemli gelişmeler olduğu sonucuna varılmıştır (1). Düşük ve yüksek gerçeklikli simülasyon yöntemlerinin karşılaştırıldığı başka bir çalışmanın sonuçları, öğrencilerin kullanılan simülasyon yönteminden bağımsız olarak memnuniyet duyduğunu göstermektedir (12). Sanal gerçeklik kullanımının değerlendirildiği bir meta-analiz çalışmasında da sanal gerçekliğin bilgi gelişiminde etkili olabileceği bildirilmektedir (13). Farklı simülasyon yöntemlerinin değerlendirildiği bu çalışmaların sonuçları ile, öğrenme hedef ve sonuçlarına uygun şekilde planlanmış simülasyona dayalı eğitimin geleneksel öğrenme yöntemlerinden daha etkili olduğu görülmektedir.

Bir simülasyon deneyimi, yazılı simülasyon vakalarını, üç boyutlu modelleri, bilgisayar yazılımını, standartlaştırılmış hastaları, kısmi görev eğiticilerini veya yüksek gerçeklikli hasta simülatörlerini içerebilmektedir. Kullanılan bu simülasyon yöntemleri literatürde; karmaşıklık düzeyi, gerçeklik düzeyi, kullandığı arayüz veya kazandırdığı becerilere göre farklı şekillerde gruplandırılmakta ve adlandırılmaktadır. Hemşirelik eğitiminde simülasyon kullanımını ilerletmek için ise, bilgi ve fikirlerin tutarlı bir şekilde iletilmesi gerekmektedir $(14,15)$. Bu nedenle bu derlemede, hemşirelik eğitiminin önemli bir parçası haline gelen simülasyona dayalı eğitimde kullanılan yöntemlerin sınıflandırılması ve gerçeklik kavramına ilişkin görüşler ele alınmaktadır.

\section{Simülasyon Yöntemleri}

Simülasyon yöntemleri; David M. Gaba, Cant ve Cooper, Chiniara ve arkadaşları, Maran ve Glavin, Hayden ve Alinire'nin tanımına göre ele alınmıştır $(3,16-28)$

\section{David M. Gaba’nın Tanımına Göre Simülasyon Yöntemleri}

David M. Gaba simülasyon yöntemlerini; sözel simülasyon, standart hasta, görev eğiticisi, bilgisayar hasta, elektronik hasta olmak üzere beş farklı şekilde sınıflandırmıştır (3).

- Sözel Simülasyon (Rol Play): Basitçe rol oynamaktadır.

- Standart Hasta (Aktörler): Öykü alma ve fizik muayene becerileri, iletişim ve profesyonel beceri eğitimi ve değerlendirilmesinde kullanılan aktörlerdir.

- Görev Eğiticisi (Fiziksel, Sanal Gerçeklik): Sabit araçları kullanan düşük gerçeklikli simülatörlerdir. Sonuçları hassas bir şekilde yansıtmadığı için klinik gerçeklikleri düşüktür. Literatürde "task trainer" olarak isimlendirilmektedir. Kısmi Dokuz Eylül Üniversitesi Hemşirelik Fakültesi Elektronik Dergisi https://dergipark.org.tr/tr/pub/deuhfed 
görev eğiticileri, normal durumlarda veya hastalığı temsil eden vücut parçalarının basit anatomik modelleri olabilmektedir. Daha karmaşık modern cerrahi görev eğitmenleri de bu kategoriye dahildir.

- Bilgisayar Hasta (Bilgisayar Ekranı, Ekran Tabanlı "Sanal Dünya"): Bilgisayar hastaları etkileşimlidir ve yazılım tabanlı veya internet tabanlı sanal dünyanın bir parçası olabilmektedir. Bilgisayar hastalar düşük bir maliyetle birçok alanda standart hastalarla aynı işlevlere sahiptir.

- Elektronik Hasta (Klinik Ortamın Kopyalanması, Manken Tabanlı, Tam Sanal Gerçeklik): En kapsamlı simülasyon biçimi elektronik hastadır. Elektronik hastalar manken veya sanal gerçeklik bazlı olabilir ve klinik ortamı bire bir canlandirabilirler $(17-19,29)$.

\section{Cant ve Cooper'in Tanımına Göre Simülasyon Yöntemleri}

Cant \& Cooper (2010) simülasyon yöntemlerini; kısmi görev eğitmenleri, ekran tabanlı bilgisayar simülatörleri, dokunsal/haptik sistemler, sanal gerçeklik, standart hasta ve tam boyutlu simülasyon olmak üzere altı farklı şekilde ele almıştır (16).

- Kısmi görev eğitmenleri: Basit teknik ve prosedürleri öğrenmek, uygulamak ve yetkinlik kazanmak için kullanılan modeller veya mankenlerdir.

- Ekran tabanlı bilgisayar simülatörleri: Bilgi edinmek, bilgi edinme yeterliliğini değerlendirmek ve klinik bilgi ve eleştirel düşünme becerileri ile ilgili geri bildirim sağlamak için kullanılan programlardır.

- Dokunsal/Haptik sistemler: Gerçek dünya ile sanal gerçekliği birleştiren simülatörlerdir.

- Sanal gerçeklik (Virtual Reality-VR) simülasyonu: Bilgisayar tarafından oluşturulan bir ortamın, artan özgünlüğünü teşvik etmek için gelişmiş kısmi görev eğitmenleri aracılığıyla sağlanan dokunsal, işitsel ve görsel uyaranlarla birleştirilmesidir.

- Standart hastalar: Kişilere bir hastayı gerçekçi ve tutarlı bir şekilde tasvir etmeyi öğreten simüle edilmiş öğrenme deneyiminde vaka çalışmalarını ve rol oynamayı kullanmaktadır.

- Tam boyutlu simülasyon: Öğrenci eylemlerine gerçekçi fizyolojik yanıt sağlamak için programlanabilen bilgisayarlı bir tam vücut mankeni içeren simülasyondur $(16,19,29)$.

\section{Chiniara ve Arkadaşlarının Tanımına Göre Simülasyon Yöntemleri}

Chiniara ve arkadaşları (2013); bilgisayar tabanlı simülasyon, hibrit simülasyon, prosedürel simülasyon, simüle edilmiş klinik canlandırma, standart hastalar olmak üzere beş farklı şekilde sınıflandırmıştır (20).

- Bilgisayar tabanlı simülasyon: Kullanıcının ekran tabanlı bir ara yüz üzerinden simülasyonla etkileşime girdiği yöntemdir. Çeşitli öğrenme kazanımları için kullanılmaktadır.

- Hibrit simülasyon: İki veya daha fazla simülasyon yöntemini birleştiren simülasyon deneyimidir.

- Prosedürel simülasyon: Bir simülatörün, belirli psikomotor becerilerin ve bunlarla ilişkili prosedürlerin eğitimine izin verdiği simülasyon yöntemidir.

- Simüle edilmiş klinik canlandırma: Gerçek ya da simüle edilmiş ortamın önemli bir rol oynadığı ve gerçek klinik ya da çalışma ortamının yeniden canlandırıldığı simülasyon yöntemidir. Simülasyon deneyimi; aktörleri, hastaları veya hasta simülatörlerini içerebilir. Genellikle vaka yönetimi, klinik tanı ve hasta güvenliği yeterliliklerinin eğitimi için kullanılmaktadır.

- Simüle/Standart hasta: Bir aktörün, bir hastanın veya bir hasta simülatörünün gerçek bir hastanın rolünü oynadı̆̆ı simülasyon yöntemidir. Genellikle hasta yönetimi, klinik tanı ve duyuşsal hedefler konusunda eğitim için kullanılır $(19,20)$.

Maran ve Glavin 'in Tanımına Göre Simülasyon Yöntemleri

Maran ve Glavin simülasyon yöntemlerini; parça görev eğiticileri, bilgisayar tabanlı sistemler, sanal gerçeklik ve dokunsal/haptik sistemler, simüle hastalar olarak ele almıştır (21).

- Parça görev eğiticileri: Ortamın yalnızca bir bölümünü kopyalamak için tasarlanmıştır. Çoğu zaman, ancak zorunlu olmamakla birlikte, vücudun anatomik parçalarına benzemektedir. Bu modeller en yaygın olarak intravenöz kateter uygulamaları gibi temel psikomotor becerileri eğitmek için kullanılmaktadırlar. Nispeten ucuzdurlar ve bu nedenle eğitim merkezlerinde genellikle birden fazla model bulunmaktadır.

- Bilgisayar tabanlı sistemler: İnsan fizyolojisi veya farmakolojisinin yönlerini, simüle edilmiş görevleri veya ortamları modellemek ve bunlarla bir bilgisayar arayüzü aracılığıyla etkileşime izin vermek için kullanılmaktadırlar. Öğrenmenin ana odağı, klinik karar vermek için bilgiyi kullanmak ve bunları eylem halinde gözlemlemektir. Bilgisayar tabanlı sistemler nispeten ucuzdur ve birden çok öğrenci tarafından kullanılabilir, öğrenciye etkileşim sırasında veya sonrasında geri bildirim sağlayabilirler.

- Sanal gerçeklik ve dokunsal/haptik sistemler: Temel amacı, sanal nesneleri veya ortamları, doğal karşıtlarına özdeş bir şekilde tüm insan duyularına sunmaktır. Bu tür bilgisayar tarafından üretilen modeller, sanal ortamda fiziksel bir etkileşimin yerini almasına izin vermek için genellikle görev eğiticileriyle birleştirilmektedir.

- Simüle hastalar: Simüle hastalar, muhtemelen en yüksek gerçeklikli simülasyondur. Bununla birlikte, kullanımları esas olarak iletişim ve kişilerarası becerilerin öğretilmesiyle sınırlıdır. Kısmi görev eğitmenleri ve simüle hastalar, teknik beceri eğitiminin psikolojik gerçekliğini artırmak için kullanılmaktadır.

- Simüle ortamlar: Multiprofesyonel ekiplerin birlikte çalışabilecekleri simüle edilmiş hastane ortamı oluşturularak güçlü bir öğrenme deneyimi ile öğrenenlere bir ekip içindeki rollerini inceleme fırsatı vermektedir. 
Entegre simülatörler:Entegre simülatörler, mankenleri yaşam bulgularını üretmeye ve monitörlere fizyolojik sinyaller göndermeye 'yönlendiren' bilgisayarlarla müdahalelerin gerçekleştirileceği kısmi veya tüm vücut mankenlerini birleştirir. Fiziksek gerçekliğin derecesi hem mankenin hem de onu çalıştıran bilgisayarın karmaşıklık düzeyine bağlıdır. Bu simülatörün seviyesini tanımlamak için birçok terim kullanılmasına rağmen, bunlar en kolay şekilde bilgisayar modelleme seviyesi açısından, eğitmen güdümlü ve manken güdümlü olarak sınıflandırılmaktadırlar:

- Eğitmen güdümlü simülatörler: Dinamik bir sistem oluşturmak amacıyla, bilimsel olarak türetilmiş solunum ve kardiyovasküler sistem modelleri ile kapsamlı farmakolojik modeller tarafindan yönlendirilen bilgisayar programlarıyla karmaşık yaşam benzeri mankenleri birleştirir. Bu simülatörler, gerçek klinik ortamda olduğu gibi "hasta" ile etkileşime girilmesine izin verir. Mankende bulunan hoparlör, "hastanın" konuştuğu izlenimini yaratır ve nabız, akciğer ve kalp sesleri, gözbebeği reaksiyonları ve idrar çıkışı gibi fiziksel durumlar üretilebilir.

- Model güdümlü simülatörler: Bu simülatörler, kısmi veya tam vücut mankenlerini daha az karmaşık bilgisayar programlarıyla birleştirir. Genel olarak, bilgisayar yazılımı, standart klinik monitör yerine bir bilgisayar ekranında görüntülenen fizyolojik sinyaller üretir ve hasta yanıtlarını yansıtacak şekilde işaretleri ayarlaması için bir eğitmen gerekir. Bu, simülatör nispeten düşük maliyetleri nedeniyle, bölgesel veya bireysel hastane düzeyinde eğitim amaçlı satın alınmaktadır (19,21-23,29).

\section{Hayden' in Tanımına Göre Simülasyon Yöntemleri}

Hayden (2010) simülasyonu manken veya senaryonun gerçeklik düzeylerine göre düşük, orta ve yüksek gerçeklikli olarak tanımlamıştır (28).

- Düşük Gerçeklikli Simülasyon (Task Trainers): Yalnızca prosedürel becerileri uygulamak için seçilen gereksinimleri karşılayan sınırlı işlevleri olan kısmi görev eğitmenlerine düşük gerçeklik simülatörleri denilmektedir. Belirli bir psikomotor beceri için tasarlanmış bir uzuv parçası manken örnek olarak gösterilebilir (intravenöz kateter uygulaması için bir kol).

- Orta Gerçeklikli Simülasyon: Gögüs hareketleri olmadan akciğer sesleri gibi insan niteliklerine sahip bir tam vücut simülatörü kullanan hasta bakımı senaryosunu oluşturmaktadır. Orta gerçeklikli simülasyon, akciğer sesleri, kalp sesler, bağırsak sesleri veya simüle kan akımı sunan, ancak gerçekçi bir ortamın özgünlüğünden yoksun olan mankenlerin veya görev eğiticilerinin kullanılmasıdır. Ekip çalışması ve liderlik gibi teknik ve teknik olmayan becerilerin eğitimi için uy gun maliyetli bir yöntemdir.

- Yüksek Gerçeklikli Simülasyon: Göğüs hareketleri ile birlikte akciğer sesleri oluşturabilen, duygusal ve psikomotor değişikliklere yanıt verecek şekilde programlanabilen standart bir hasta veya tam vücut hasta simülatörü kullanan hasta bakımı senaryolarından oluşmaktadır 20. Yüksek gerçeklikli simülasyon ile eğitimciler birçok hasta durumunu kopyalayabilir ve öğrenciler hemşirelik becerilerini hastaları tehlikeye atmayan bir ortamda geliştirebilir ve uygulayabilir. Bu teknolojiyi kullanılarak sunulabilecek sonsuz sayıda gerçekçi senaryo bulunmaktadır. Klinik durumda kullanılanlarla aynı olan monitörler, yaşam bulgularında meydana gelen değişiklikleri kopyalayabilir. "Hasta", teknik ve farmakolojik müdahalelerle tam ve gerçekçi bir şekilde canlandırılabilir $(24,25,28)$.

\section{Alinier'in Tanımına Göre Simülasyon Yöntemleri}

Alinier (2007) simülasyon yöntemlerini teknoloji düzeylerine göre altı farklı seviyede sınıflandırmıştır (26).

- Yazılı Simülasyonlar (Seviye 0): Genellikle sınıf ortamında, kalem ve kâğıdın kullanıldığı düşük bütçeli, öğrenci yönetiminde, hasta problemlerinin ele alındığı ve tanı temelli değerlendirmenin yapıldığı simülasyon yöntemidir.

- Üç Boyutlu Modeller (Seviye 1): Basit bir manken, kısmi görev simülatörleri veya düşük gerçeklikli simülasyon modellerinin kullanıldığı, öğrenci ya da eğitimcinin yürüttüğü modellerdir. Genellikle psikomotor becerilerin eğitiminin yürütüldüğü simülasyon yönteminde etkileşim sınırlı olmaktadır.

- Ekran Tabanlı Simülatörler (Seviye 2): Bilgisayar simülasyonları, simülasyon yazılımları, videolar, DVD'ler, sanal gerçeklik ve cerrahi simülatörlerin kullanıldığı etkileşimli simülasyon yöntemidir. Nispeten düşük bütçeli bu yöntemde, bir eğitimci çok sayıda öğrenci ile simülasyonu yürütebilir ve öğrenciler kişisel bilgisayarlarında kendi başlarına uygulayabilirler.

- Standart Hastalar (Seviye 3): Gerçek ya da simüle edilmiş hastalar (eğitimli aktörlerin hasta rolünü yaptığı) ile yürütülen psikomotor, bilişsel ve kişiler arası ilişkilerin eğitiminin yapılabildiği simülasyon yöntemleridir. Bu yöntemde, kullanılan malzemeler senaryoya göre değişiklik göstermektedir.

- Orta Gerçeklikli Hasta Simülatörleri (Seviye 4): Bilgisayar kontrollü, programlanabilir, tam vücut boyutunda tamamen etkileşimli olmayan hasta simülatörleridir. Gerçekçi bir deneyim sağlayan orta gerçeklikli hasta simülatörleri çok çeşitli becerileri uygulamak için kullanılabilirler ve genellikle taşınabilirdirler.

- İnteraktif Hasta Simülatörleri (Seviye 5): Yüksek gerçeklikli simülatör olarak da bilinmektedir. Gerçekçi bir ortamda yürütülen interaktif hasta simülatörleri gerçekçi bir deneyim sağlar ve çok çeşitli beceriler için kullanılabilirler (19,26,27).

Literatürde farklı simülasyon yöntemlerinin kullanıldığı birçok çalışma bulunmaktadır. Yüksek gerçeklikli simülasyon, standart hasta ve görev eğiticisi ile hemşirelik öğrencilerinin bilgi, beceri, stres, memnuniyet ve özgüven düzeyleri değerlendirildiği bir çalışmada, her üç yöntemde de öğrencilerin bilgi düzeylerinin arttığı gözlemlenmiştir. Standart hasta grubundaki öğrencilerin stres düzeyleri ve öğrenme memnuniyet puanları diğerlerine göre daha yüksek bulunmuştur. Kısmi görev eğiticisi grubundaki öğrencilerin öğrenme konusunda daha düşük özgüven puanları elde edilmiştir. Öğrencilerin standart hasta uygulamasında beceri puanları diğerlerine göre daha düşük bulunmuştur (30). Bilgisayar tabanlı simülasyon ve manken 
tabanlı simülasyon yöntemlerinin karşılaştırıldığı bir başka çalışmada, her iki grupta olumlu öz-yeterlik ve memnuniyet bildirilmiştir. Bilgisayar tabanlı simülasyon yoluyla öğrenme, manken tabanlı simülasyona kıyasla, karar verme ve hemşirelik becerilerini uygulamada daha yüksek memnuniyetle sonuçlanmıştır (31). Çalışmaların sonuçları ile, kullanılan simülasyon yöntemlerinin hemşirelik öğrencileri üzerinde farklı yönlerde elde edilen olumlu etkileri görülmektedir.

Hemşirelik eğitiminde simülasyon yöntemlerinin kullanıldığı çalışmalara bakıldığında, birbirinden farklı yöntemlerin farklı sınıflandırmalar altında kullanıldığı görülmektedir. Çalışmalarda parça görev eğiticileri, yüksek gerçeklikli simülasyon yöntemi, standart hasta, üç boyutlu simülasyon yöntemi, orta ve yüksek gerçeklikli simülasyon yöntemi, sanal standart hasta yöntemi, insan hasta simülatörlerinin hemşirelik öğrencilerindeki bilgi, beceri, stres, memnuniyet gibi değişkenleri değerlendirmek için kullanıldığı görülmektedir. Yapılan çalışmaların ortak özelliği ise, simülasyon yönteminin hangi sınıflandırmaya uygun olarak adlandırıldığına atıfta bulunulmamış yalnızca uygulanılan yöntemden bahsetmiş olmasıdır. Bazı çalışmalarda, aynı yöntemin farklı isimlerle tanımlandığ 1 da bildirilmektedir (30,32-36).

\section{Simülasyonda Gerçeklik Kavramı Hakkındaki Farklı Görüşler}

Gerçeklik kavramı, hedeflenen beceri veya becerilerin, simüle edilen deneyimde yakalanma derecesidir. Bu tanım, simülatörlerin tasarlanmasında yararlı bir kılavuz olsa da teknolojik gelişmeleri ve eğitimsel etkinlik ilkeleri üzerindeki fiziksel benzerliği vurgulamaktadır (21,37). 1999 yılında, Simulation Interoperability Standards Organization/ Simülasyon Birlikte Çalışabilirlik Standartları Organizasyonu (SISO) oluşturduğu raporda ise, gerçeklik kavramının çok boyutlu olduğu bu nedenle ölçülebilir hale getirilmesi gerektiği belirtilmiştir (38). Gerçekliğin ölçülebilir hale getirilmesi için ise; gerçekliğin standardı, taksonomisi, özellikleri, gerekli seviyesinin belirlenmesi gerekmektedir (20).

Maran ve Glavin (2003) gerçeklik kavramının kullanımında tutarsızlıklar bulunduğunu ve bu tutarsızlıkların kafa karışıklığına neden olduğunu öne sürmektedir. Gerçekliği, simülatörün görünümü ve davranışının, simüle edilen sistemin görünümü ve davranışıyla ne ölçüde eşleştiğidir şeklinde tanımlamıştır ve Miller'in (1953) tanımındaki fiziksel/mühendislik ve psikolojik/işlevsel gerçeklik olarak ele almaktadır (21,39). Fiziksel gerçeklik, eğitim cihazının veya ortamının gerçek görevin fiziksel özelliklerini çoğaltma derecesidir. Simülatörün fiziksel gerçekliğinin artırılması, kaçınılmaz olarak maliyette artışlara yol açacaktır. Psikolojik/işlevsel gerçeklik, gerçek görevdeki beceri veya becerilerin simüle edilen görevde yakalanma derecesidir. Gereken gerçeklik seviyesi, görevin türüne ve eğitimin aşamasına bağlıdır ve beceri aktarımını etkilemektedir. Her seviyede hem fizyolojik hem de psikolojik gerçekliği artırmak için farklı simülatör türleri birleştirilebilir (21).

Chiniara ve arkadaşları (2013) yaptığı gerçeklik tanımını ise Hayden'den (2010) farklı şekilde ele almıştır. Bu tanımda gerçekliğin sayısal bir ölçü ile ifade edilemeyeceği, gerçekliği belirlemek için özeliklerinin tanımlanması gerektiğinden bahsedilmiştir. Gerçeklik; fiziksel gerçeklik, ortam gerçekliği ve geçici gerçeklik olarak üç boyutta ele alınmıştır (20).

1. Fiziksel gerçeklik/ hasta gerçekliği: Simülasyonda oluşturulan hasta özelliklerinin gerçek dünya ile uyuşma derecesini açıklamaktadır. Fiziksel gerçekliği ölçmek için çözünürlük ve doğruluk olmak üzere iki farklı şekilde raporlanabilir. Çözünürlük, gerçek dünyadan gerekli bir özelliğin simülasyonda yeniden oluşturulup oluşturulamadığıdır. Doğruluk ise, gerçek dünyanın bir özelliğinin simülasyonda yeniden oluşturulabilme derecesini ifade etmektedir.

2. Ortam gerçekliği: Simülasyonda oluşturulan ortam özelliğinin gerçek dünyanın özellikleriyle ne kadar yakından eşleştiğini açıklamaktadır.

3. Zamansal gerçeklik: Gerçekliğe kıyasla simülasyonda zamanın ne kadar yakın aktığını açıklamaktadır. Bu düzey için de çözünürlük ve doğruluk olmak üzere iki ölçüm kullanılabilmektedir (20).

Hamstra ve arkadaşlarının (2014) gerçeklik terimini ele aldığı çalışmasında ise, değerlendiriciler arasındaki ve hatta puanlayıcılar içindeki uygunluğu asla tutarlı bir şekilde tanıyamadıkları görülmektedir. Bunun nedeni olarak, gerçeklik kavramının hareketli bir hedef gibi görünmesi bildirilmiştir. Farklı yazarlar aynı simülatörü, simülatörün görsel, işitsel, dokunsal veya işlevsel özelliklerini vurgulamalarına ve ayrıca öğrencilere, öğrenme hedeflerine ve öğrenme bağlamına bağlı olarak yüksek veya düşük gerçeklik şeklinde tanımlamışlardır (37).

Kim, Park ve Shin'in (2016) hemşirelik eğitiminde gerçeklik düzeyine göre simülasyon kullanımını değerlendirdiği metaanaliz çalışmasında, simülasyona dayalı eğitimin özellikle psikomotor beceri alanında büyük etkilere sahip olduğu ancak, etkisinin gerçeklik düzeyiyle orantılı olmadığını göstermiştir. Bu nedenle, eğitimin hedef ve sonuçlarına göre uygun gerçeklik düzeyinde uygun simülasyon yönteminin kullanılması önem taşımaktadır (40).

\section{Sonuç}

Uluslararası Hemşirelik Klinik Simülasyon ve Öğrenme Derneğinin (INACSL) (2016), simülasyona dayalı eğitimde en iyi uygulama standartları ile, tutarlı terminoloji ve standart bir dil kullanımına katkı sağlaması amaçlanmıştır (41). Ancak simülasyon yöntemleri ve gerçeklik kavramı ile ilgili farklı sınıflandırmaların ve tanımların bulunduğu görülmektedir. Bu tanım ve sınıflandırmalar, birbirine benzer olsa da aralarında farklılıklar söz konusudur. Gerçeklik kavramının ise, uygun simülasyon yönteminin seçiminde önemli rol oynadığı görülmektedir. Simülasyon yöntemi ve gerçeklik düzeyinin seçimi de eğitimin hedef ve sonuçları, öğrenci seviyesi ve kolaylaştırıcı gibi faktörlere bağlıdır (42). Farklı gruplara, farklı simülasyon yöntemleri ve farklı gerçeklik düzeyinde uygulama yapılması simülasyona dayalı eğitimde beklenen bir sonuçtur. Ancak, simülasyon yöntemlerinin tamamını içine alan, tüm gruplar için genel geçer, ortak bir dilin kullanıldığ tanımlara ihtiyaç olduğu görülmektedir.

Bu derlemede, simülasyona dayalı eğitimde kullanılan yöntemlerin sınıflandırılması ve gerçeklik kavramına ilişkin görüşler, simülasyona dayalı hemşirelik eğitiminin planlanmasına rehberlik sağlaması açısından ele alınmıştır.

Simülasyon yöntemlerine ilişkin farklılıkların olması, aynı yöntemin farklı isimlerle tanımlanması gibi durumlar karışıklığa ve terminolojik tutarsızlığa neden olmaktadır. Bunun için terminoloji kullanımında; 
- Simülasyon yöntemlerinin sınıflandırılmasının gerçeklik düzeyini içerecek şekilde olması,

- Gerçeklik düzeyinin; kullanılan simülasyon yöntemini, ortamı ve zamanı da ele alacak şekilde tanımlanması,

- Farklı isimlerle yapılan aynı simülasyon yöntemlerine ilişkin tanımlamaların önüne geçilmesi için; INACSL ve SSH tarafından hazırlanan sözlüklerden yararlanılması,

- Yapılan çalışmalarda, yalnızca uygulanılan yöntemin isminden bahsetmek yerine, yönteminin hangi sınıflandırmaya uygun olarak adlandırıldığına da atıfta bulunulması önerilmektedir.

\section{Bilgilendirme}

Yazarların Katkı Beyanı: Fikir/Kavram: GŞK, TB, Tasarım: GŞK, TB, Denetleme/Danışmanlık: TB, Kaynak Taraması: GŞK, Makalenin Yazımı: GŞK, TB, Eleştirel Düşünme: GŞK, TB, şeklindedir. Yazarlar arasında çıkar çatışması bulunmamaktadır. Bütün yazarlar bu makalenin son halini onaylamaktadır. Bu çalışmada finansal destek alınmamıştır. Araştırmanın bütçesi araştırmacılar tarafından karşılanmıştır. 


\section{Kaynaklar}

1. Shin S, Park JH, Kim JH. Effectiveness of patient simulation in nursing education: meta-analysis. Nurse Education Today 2015;35(1):176-82.

2. Konrad S, Fitzgerald A, Deckers C. Nursing fundamentals - supporting clinical competency online during the COVID-19 pandemic. Teaching and Learning in Nursing 2021;16(1):53-6.

3. Gaba DM. The future vision of simulation in health care. Quality and Safety in Health Care 2004;13(SUPPL. 1):2-10.

4. Bashaw M. Integrating Simulations Into Perioperative Education for Undergraduate Nursing Students. AORN Journal 2016;103(2):212.e1-212.e5.

5. Jones F, Passos-Neto C, Melro Braghiroli O. Simulation in medical education: Brief history and methodology. Principles and Practice of Clinical Research Journal 2015;1(2):56-63.

6. Sezer H, Orgun F. Hemşirelik eğitiminde simülasyon kullanımı ve simülasyon modeli. Ege Üniversitesi Hemşirelik Fakültesi Dergisi 2017;33(2):140-52.

7. Agu CF, Stewart J, McFarlane-Stewart N, Rae T. COVID-19 pandemic effects on nursing education: looking through the lens of a developing country. International Nursing Review 2021;68(2):153-8.

8. INACSL, SSH. Position Statement on Use of Virtual Simulation during the Pandemic _ The Society for Simulation in Healthcare 2020. URL: https://www.ssih.org/COVID-19-Updates/ID/2237/COVID-19-SSHINACSL-Position-Statement-on-Use-ofVirtual-Simulation-during-the-Pandemic

9. Huun K. Virtual Simulations in online nursing education: align with quality matters. Clinical Simulation in Nursing 2018;22:2631.

10. Rim D, Shin H. Effective instructional design template for virtual simulations in nursing education. Nurse Education Today 2021;96:104624.

11. Boz Yüksekdağ B. Covid-19 pandemisi döneminde öğrenme ve uzaktan hemşirelik eğitiminde paradigma değişimi. Açıköğretim Uygulamaları ve Araştırmaları Dergisi 2021;7(1):61-73.

12. Tosterud R, Hedelin B, Hall-Lord ML. Nursing students' perceptions of high- and low-fidelity simulation used aslearning methods. Nurse Education in Practice 2013;13(4):262-70.

13. Chen FQ, Leng YF, Ge JF, Wang DW, Li C, Chen B, et al. Effectiveness of virtual reality in nursing education: Meta-analysis. Journal of Medical Internet Research 2020; 15:22(9).

14. Durmaz Edeer A, Dicle A. Use of simulation in nursing education and simulation types. Hemşirelikte Eğitim ve Araştırma Dergisi 2015;12(2):121-5.

15. Meakim C, Boese T, Decker S, Franklin AE, Gloe D, Lioce L, et al. Standards of best practice: simulation standard I: terminology. Clinical Simulation in Nursing 2013;9(6 SUPPL):3-11.

16. Cant RP, Cooper SJ. Simulation-based learning in nurse education: systematic review. Journal of Advanced Nursing 2010;66(1):3-15.

17. Cooper JB, Taqueti VR. A brief history of the development of mannequin simulators for clinical education and training. Postgraduate Medical Journal 2008;84(997):563-70.

18. Oermann MH, Shellenbarger T, Gaberson KB. Clinical Teaching Strategies in Nursing. Oermann MH, Shellenbarger T, Gaberson KB, Springer Publishing Company; 2017. 188-194.

19. Nehring WM, Lashley FR. Nursing Simulation: A Review of the Past 40 Years. Simulation \& Gaming. 2009;40:528-52.

20. Chiniara G, Cole G, Brisbin K, Huffman D, Cragg B, Lamacchia M, et al. Simulation in healthcare: A taxonomy and a conceptual framework for instructional design and media selection. Medical Teacher 2013;35(8).

21. Maran NJ, Glavin RJ. Low- to high-fidelity simulation - a continuum of medical education? Medical Education, Supplement 2003;37(1):22-8.

22. Ker J, Mole L, Bradley P. Early introduction to interprofessional learning: a simulated ward environment. Medical education. 2003; 37(3):248-55.

23. Jenson CE, Diane Mcnally Forsyth C. Virtual Reality Simulation Using Three-dimensional Technology to Teach Nursing Students. Computers, Informatics, Nursing. 2012;30(6):312-8.

24. Hayden JK, Smiley RA, Alexander M, Kardong-Edgren S, Jeffries PR. The NCSBN national simulation study: a longitudinal, randomized, controlled study replacing clinical hours with simulation in prelicensure nursing education. Journal of Nursing Regulation 2014;5(2):3-40.

25. Ntlokonkulu ZB, Rala NM deline, Goon D ter. Medium-fidelity simulation in clinical readiness: A phenomenological study of student midwives concerning teamwork. BMC Nursing. 2018;17(1):1-8.

26. Alinier G. A typology of educationally focused medical simulation tools. Medical Teacher 2007;29(8):243-50.

27. Kaboudian A, Cherry EM, Fenton FH. Real-time interactive simulations of large-scale systems on personal computers and cell phones: Toward patient-specific heart modeling and other applications. Science Advances. 2019;5(3).

28. Hayden J. Use of Simulation in nursing education: national survey results. Journal of Nursing Regulation 2010;1(3):52-7.

29. Sendir M, Dogan P, Karacay P, Tarhan M, Yılmaz Coşkun E, Kolcu G. Healthcare Simulation Dictionary (Turkish version) Sağlık Bakımında Simülasyon Sözlük. 2nd Edition. The Agency for Healthcare Research and Quality (AHRQ) Society Simulation for Healthcare; 2020. URL: https://www.ssih.org/dictionary

30. Üzen Cura Ş, Kocatepe V, Yıldırım D, Küçükakgün H, Atay S, Ünver V. Examining knowledge, skill, stress, satisfaction, and self-confidence levels of nursing students in three different simulation modalities.Asian Nursing Research 2020; 14(3): 158-64. 
31. Roh YS, Lee WS, Chung HS, Park YM. The effects of simulation-based resuscitation training on nurses' self-efficacy and satisfaction. Nurse Education Today 2013;33(2):123-8.

32. Levett-Jones T, Everson N, Lapkin S. Exploring the impact of a 3D simulation on nursing students' intention to provide culturally competent care. Clinical Simulation in Nursing 2019;36:22-9.

33. Hauze SW, Hoyt HH, Frazee JP, Greiner PA, Marshall JM. Enhancing nursing education through affordable and realistic holographic mixed reality: The virtual standardized patient for clinical simulation. Advances in Experimental Medicine and Biology 2019;1120:1-13.

34. Baptista RC, Paiva LA, Gonçalves RF, Oliveira LM, Pereira MF, Martins JC. Satisfaction and gains perceived by nursing students with medium and high-fidelity simulation: A randomized controlled trial. Nurse education today 2016;46:127-32.

35. Shinnick MA, Woo MA, Mentes JC. Human patient simulation: state of the science in prelicensure nursing education. The Journal of nursing education 2011;50(2):65-72.

36. Gates MG, Parr MB, Hughen JE. Enhancing nursing knowledge using high-fidelity simulation. Journal of Nursing Education. 2012;51(1):9-14.

37. Hamstra SJ, Brydges R, Hatala R, Zendejas B, Cook DA. Reconsidering fidelity in simulation-based training. Academic Medicine 2014;89(3):387-92.

38. Gross DC. Report from the fidelity implementation study group. simulation interoperability standards organization - simulation interoperability workshop.

1999.

URL: https://www.sisostds.org/DesktopModules/Bring2mind/DMX/API/Entries/Download?Command=Core_Download\&EntryId=3 2793\&PortalId $=0 \&$ TabId $=105$

39. Miller RB. Psychological considerations in the design of training equipment. Distribution. 1954. URL: https://apps.dtic.mil/dtic/tr/fulltext/u2/071202.pdf

40. Kim J, Park JH, Shin S. Effectiveness of simulation-based nursing eucation depending on fidelity: a meta analysis. BMC Medical Education 2016;16(1):1-8.

41. INACSL. INACSL Standards of Best Practice: SimulationSM Simulation Glossary. Clinical Simulation in Nursing. 2016;12:S39-47.

42. Munshi F, Lababidi H, Alyousef S. Low- versus high-fidelity simulations in teaching and assessing clinical skills. Journal of Taibah University Medical Sciences 2015;10(1):12-5. 